\title{
Correction to: Sentinel Node Biopsy in Oral Cancer
}

\author{
Krishnakumar Thankappan and Moni Abraham Kuriakose
}

\section{Correction to: Chapter 8 in: M.A. Kuriakose (ed.), Contemporary Oral Oncology, https://doi.org/10.1007/978-3-319-14917-2_8}

The original version of this chapter did not state that permission was received to reuse text from the following sources:

- Kuriakose MA, Trivedi NP. Sentinel node biopsy in head and neck squamous cell carcinoma. Current Opinion in Otolaryngology \& Head and Neck Surgery. 2009;17:100-10. https://doi.org/10.1097/MOO.0b013e3283293631. https:// journals.lww.com/cootolaryngology/Fulltext/2009/04000/Sentinel_node_ biopsy_in_head_and_neck_squamous.7.aspx\#pdf-link.

- Monroe MM, Lai SY. Sentinel Lymph Node Biopsy for Oral Cancer: Supporting Evidence and Recent Novel Developments. Curr Oncol Rep. 2014;16:385. https://doi.org/10.1007/s11912-014-0385-1.

- Trivedi NP, Ravindran HK, Sundram S, Iyer S, Kekatpure V, Durah S, Kuriakose MA. Pathologic evaluation of sentinel lymph nodes in oral squamous cell carcinoma. Head \& Neck. 2010;32(11):1437-43. https://doi.org/10.1002/hed.21345.

- Shellenberger TD. Sentinel Lymph Node Biopsy in the Staging of Oral Cancer. 2006;18(4):547-63. https://doi.org/10.1016/j.coms.2006.06.012.

The authors have obtained retrospective permission to use these sources and this correction has been updated in chapter 8 .

The updated online version of this chapter can be found at https://doi.org/10.1007/978-3-319-14917-2_8 